\title{
INTRODUÇÃO AO SUBLIME EM LONGINO
}

\author{
INTRODUCTION TO SUBLIME IN LONGINUS
}

Yves São Paulo*

\section{RESUMO}

Peri Hypsous é o mais antigo tratado sobre o sublime a chegar às nossas mãos. Apesar de seminal para os estudos concernindo ao sublime, o texto referenciado como sendo de autoria de Longino sofreu com influências externas ditando o recebimento de suas proposições. A principal dessas influências consiste em demarcar o texto de Longino como uma obra pertencente à retórica romana, levando a ressaltar determinadas características do texto e diminuir outras. O presente artigo revisita sua história, desde a querela envolvendo a identidade do autor, até as variantes interpretativas de sua inserção no universo da retórica. Também será interpretada a relação do termo grego Hypsos, traduzido por sublime, com a noção de Logos e as implicações filosóficas dessa relação. Ao relacionar Hypsos com Logos, o tratado de Longino se posiciona divergente aos demais tratados retóricos sobre arte, abordando um sentimento natural com repercussões éticas.

PALAVRAS-CHAVE: Longino; sublime; retórica; estética.

\section{ABSTRACT}

Peri Hypsous is the oldest treatise on the sublime to reach our hands. Despite being seminal for studies concerning the sublime, the text referred to as being by Longinus suffered from external influences dictating the reception of his propositions. The main one of these influences is to demarcate Longinus' text as a work belonging to Roman rhetoric, leading to highlighting certain characteristics of the text and diminishing others. This article revisits its history, from the quarrel involving the author's identity, to the interpretative variants of its insertion in the universe of Roman rhetoric. It will also be interpreted the relation of the Greek term Hypsos, translated by sublime, with the notion of Logos and the philosophical implications of this relation. By relating Hypsos to Logos, Longinus' treatise is at odds with other rhetorical treatises on art, addressing a natural feeling with ethical repercussions.

KEYWORDS: Longinus; sublime; rhetoric; aesthetics.

Peri Hypsous, ou Do sublime é o texto mais antigo a respeito dessa noção a chegar aos tempos atuais. Realizar uma introdução a seu respeito implica não somente incorrer em interpretações de seu conteúdo, como também reconhecer a história envolvendo sua escrita, suas traduções; enfim, sua viagem no tempo até chegar aos leitores do século XXI.

Apesar de seminal para os estudos concernindo ao sublime, o texto referenciado como sendo de autoria de Longino sofreu com influências externas ditando o recebimento de suas

\footnotetext{
* Mestre em Filosofia pela. Universidade Federal da Bahia (UFBA); Doutorando em Filosofia pela mesma instituição. E-mail: yvessaopaulo@gmail.com.
} 
proposições. A principal dessas influências consiste em demarcar o texto de Longino como uma obra pertencente à retórica romana, levando a ressaltar determinadas características do texto e diminuir outras. A discussão sobre a categorização de Do sublime como obra retórica ou não será um dos tópicos discutidos mais à frente.

Para além da situação de Do sublime no meio da tradição de estudos literários/estéticos/das artes, serão apontados os esforços de autores mais recentes, em especial Robert Doran, em reinterpretar o texto clássico de Longino. Uma das características mais comuns desses estudos recentes é a recusa de trabalhar a noção de Longino tal como traduzida pelos latinos. Ao invés de diretamente utilizar o termo sublime - sem de todo abandoná-la, respeitando a história do termo e a influência de Longino - , tais autores preferem a leitura mais aproximada do original grego hypsos.

Ao retomar o termo grego, esses autores apontam para particularidades da formulação de Longino que foge ao uso de sublime, tal como extrapola a noção de ser esse um texto pertencente à tradição retórica. Veremos quais são essas particularidades do termo Hypsos, e como a reinterpretação da obra de Longino pode fazê-la mais relevante para os estudos estéticos.

\section{I}

A filosofia guarda muitos mistérios, não somente na interpretação das obras de diversos autores, também na origem de determinadas obras. No caso particular de Do sublime, o mistério abarca a origem da obra — de data de composição imprecisa —, assim como quem teria sido seu autor.

O nome frequentemente dado ao autor da obra é Longino, num equívoco de atribuição da autoria do texto. O mais antigo manuscrito existente a fazer referência a Do sublime encontra-se preservado na Biblioteca Nacional da França. Nele é possível encontrar a suposição de dois possíveis autores ao referido texto: Dionysius ou Longinus. A confusão consistiu em ignorar a partícula $o u$, procedendo por indicar como autor esta personagem agora chamada Dionísio Longino. Em seu extenso estudo sobre o sublime, Robert Doran aponta que a confusão passou despercebida até meados da primeira década de 1800, quando o acadêmico italiano Girolamo Amati se deparou com o manuscrito no Vaticano onde a partícula ignorada ou se fazia presente (DORAN, 2015, p. 30, nota 17). 
Os dois nomes mencionados no manuscrito do século $\mathrm{X}$ fazem indicação a duas figuras proeminentes da cultura romana, de biografia conhecida. O primeiro seria Dionísio de Halicarnassus, retórico e historiador; o segundo, Cássio Longino, filósofo e conselheiro político. As obras de Cássio Longino se perderam com a passagem do tempo, mas são mencionadas por alguns de seus alunos e seguidores. Pelo conteúdo apontado por essa bibliografia, especialmente pelos comentários à obra de Platão presentes nos seus escritos filosóficos, Cássio Longino foi atribuído como sendo o autor de Do Sublime. O nome do autor procedeu a ser chamado por Cássio Dionísio Longino a partir de então, novamente sem comprovação (DORAN, 2015, p. 30-31) - ignorando as diferenças entre as interpretações da filosofia platônica realizadas por Cássio Longino e aquelas presente em Do sublime.

\section{II}

Logo no primeiro parágrafo do texto, Longino cita dois nomes distintos que apontarão o rumo de seu texto. O primeiro, Cecílio de Calacte, a quem Longino atribui a escrita de tratado sobre o sublime - portanto, servindo Do sublime como documentação para indicar a existência do debate em torno da noção anterior à sua escrita. A respeito do tratado de Cecílio pouco se sabe para além do que é referenciado por Longino. O segundo nome é Postúmio Terenciano, tradicionalmente identificado como sendo um jovem romano de origem nobre, aluno de Longino.

O favorecimento da interpretação de Postúmio Terenciano como aluno de Longino vem logo em seguida, com o autor escrevendo: "quando em conjunto o analisamos" o texto de Cecílio sobre o sublime, "pareceu-nos não estar à altura do assunto que trata" (LONGINO, 2015 , p. 35, 1.1). Essa passagem seria indicativa de uma atividade realizada entre aluno e mestre de leitura e análise do texto, posteriormente levando a uma discussão do modelo mais apropriado para encarar o sublime.

Do sublime, portanto, nasce com o propósito de obra pedagógica intentando por melhor significar o sentido de sublime — tal como já discutido anteriormente entre estas duas personagens, Postúmio Terenciano e Longino. Propósito apontado por Philip Shaw como problemático, uma vez que o sublime apresentado por Longino nas páginas seguintes será referenciado como não aprendido: "não se aprende o sublime; se apreende, como um contágio divino" (SHAW, 2006, p. 13). 
Em 1.4 de Peri Hypsous, Shaw encontra uma passagem de Longino pronta para confirmar suas suspeitas: "pois se, em geral, a persuasão depende de nós”, escreve Longino, “o sublime impõe-se a nós e fica acima de qualquer ouvinte" (LONGINO, 2015, p. 37, 1.4). Há algo no sublime que pertence à técnica de composição de um texto, mas o mais importante é uma qualidade não aprendida — tanto por autor quanto por ouvinte/leitor.

O sublime não é construído seguindo regras retóricas, como se crescesse ao longo do texto com a incrementação de passagens até levar ao êxtase do leitor; pelo contrário, "o raio e trovão do sublime pode emergir de uma única frase" (SHAW, 2006, p. 13). A competência de ser dominado por este instante fugidio e breve de uma frase extasiante também não pode ser ensinado, uma vez que essa dominação do leitor acontece de maneira involuntária.

Descrição que sugere o sublime como sendo antes um "produto da natureza do que um produto da arte" (SHAW, 2006, p. 14). Apesar dessa suspeita, Longino apontará — relembra o próprio Shaw - que a força da natureza a ordenar sentimentos e emoções trabalha de modo todo próprio: “em outras palavras, sentimentos podem surgir da natureza, mas é preciso que a arte lhes dê forma e coerência" (SHAW, 2006, p. 14).

A crítica de Longino ao tratado de Cecílio, no primeiro parágrafo de Do sublime, apontava para a falta de método para chegar até ao assunto tratado. Portanto, escrever sobre o sublime, mesmo quando sua conclusão indica uma incapacidade de aprendizado em poder experimentar tal sentimento voluntariamente, também incorre em como "podemos conduzir a nossa própria natureza a um certo grau de elevação" (LONGINO, 2015, p. 36, 1.1).

Essa indicação de métodos aptos a "dar forma", nas palavras de Shaw, ao sublime pode igualmente ser utilizada num texto sem levar ao sentimento desejado. Longino segue em suas páginas subsequentes a apresentar diferentes dispositivos que podem ser utilizados para alcançar o efeito do sublime, mas esses mesmos dispositivos (hipérbole, perífrase, comparações, símiles, metáfora) foram e são inúmeras vezes empregados na produção de discursos sem alcançar o sublime (SHAW, 2006, p. 14). Por fim, permanece o que Boileau dizia ser um "je ne sai quoi" no sublime - em especial no sublime longiniano.

A frustração de Philip Shaw com os intentos pedagógicos de Longino reside na falta de uma definição do que seria o sublime e de como alcançá-lo, sem margem de equívoco. Uma frustração que pode ser lida na passagem: "tudo o que permanece essencial para o sublime é um estado emocional" (SHAW, 2006, p. 14) - mas será que o mesmo não valeria para toda e qualquer emoção intentada pela arte? 
A diferença do sublime para as demais emoções é o seu alcance, seu "grau de elevação". Um texto pode ser ordenado para alcançar essa alta elevação sublime, mas depende da disposição do autor e do leitor/ouvinte, não apenas de grandes temas ou técnicas. A cobrança por uma metodologia que com maior precisão leve ao sublime esbarra na visão tradicional de enxergar o texto de Longino como uma obra retórica. Assim categorizando-a, o leitor espera uma sequência discursiva tendente a apresentar-lhe uma cadeia de causas e efeitos de onde poderá tirar sua conclusão; espera métodos de composição do argumento que indiquem modos inequívocos de interpretar o sublime quando este aparecer.

A recepção do texto de Longino sob a categorização de obra retórica suscita de seus intérpretes a busca por definições mais objetivas do que o autor está disposto, ou mesmo pode dar. Desde o primeiro parágrafo do texto, Longino escreve que se trata de "como conduzir a nossa própria natureza", não havendo uma fórmula fixa de como seria possível fazê-lo.

Postúmio Terenciano, tido como aluno de Longino e a quem o texto referencia como interlocutor, é apontado pelo autor como sendo uma personagem de disposição a ser tomada pelo sublime tão logo uma obra de alta disposição cair-lhe em mãos. Portanto, o interlocutor de Longino não necessita de um passo a passo descritivo de como alcançar o sublime, uma vez que possui por conta própria a disposição para experimentá-lo, e enxergar as problemáticas da incursão de Cecílio sobre o tema ("Mas penso que esta e outras considerações semelhantes tu próprio, meu bom Terenciano, as poderia fazer, dada a tua experiência" [LONGINO, 2015, p. $37,1.4])$.

Enxergar Do sublime como pertencente à tradição retórica traz ao texto algumas dificuldades externas; há uma presunção de como sua composição deveria se comportar. A influência do estilo de texto filosófico mais comum da época é patente no texto de Longino, mas suas quebras com o formato também podem ser notadas após nova leitura.

\section{III}

Antonio López Eire, falando sobre a redenção sobre a história da retórica desde a Grécia antiga e sobre seus temas recorrentes, aponta para a existência de duas espécies de retórica. A primeira ele diz ser de perfil claramente político, abrigando discursos instrumentais de ação política. A segunda espécie de retórica é escolar, "é uma retórica [...] do indivíduo que aspira a conhecer e praticar as normas racionais de uma filosofia fortemente ética, e que procura uma formação humanística" (EIRE, 2002, p. 12, tradução nossa). 
É nesse segundo grupo que Longino e seu tratado podem ser inseridos. Estão presentes na obra de Longino ambas as características tanto de busca de formação de um indivíduo, quanto as sequenciais apresentações práticas de "normas racionais de uma filosofia ética e humanista". O tratado de Longino surge para o leitor contemporâneo como carregado de originalidade, dispensada pelo próprio texto. A noção de sublime nele presente aponta para outras formulações precedentes, de textos perdidos ao longo dos séculos. É próprio ao texto Do sublime apontar para o significado de hypsos nele exposto como sendo possuidor de significado muito bem estabelecido anteriormente, o que somente reverbera a pobreza do texto de Cecílio em conseguir ser claro a respeito de seu tópico (DORAN, 2015, p. 33).

Em artigo introdutório sobre os muitos exercícios de teorizar o sublime ao longo dos séculos, com o sugestivo título de $O$ sublime explicado às crianças em referência a JeanFrançois Lyotard, Virgínia Figueiredo escreve que, no período em que Longino se encontra, os artistas são visados pelos exercícios teóricos de retórica e poética, diferente do que acontecerá séculos mais tarde com a estética, focando na experiência proveniente do contato com as obras artísticas, com a natureza ou com a própria razão; uma afirmação arriscada de se fazer e que a autora não abraça completamente, referenciando-a ao mesmo Lyotard que lhe serve de inspiração. Ao contrário, ela escreve: "Talvez o sublime tenha participado dessa mudança" (FIGUEIREDO, 2011, p. 36) da retórica para a estética, oferecendo uma mudança de perspectiva.

A aceitação da Retórica como produtora de análises de como fazer uma obra artística, debulhando técnicas de obras literárias para demonstrar como alcançar semelhante sucesso retórico, demonstra a fragilidade da categorização de "tratado retórico" a Do sublime.

É também Virgínia Figueiredo quem aponta para a difícil separação do trabalho realizado por Longino em seu tratado daqueles realizados séculos mais tarde e categorizados sob o nome de estética. Desta vez sob a luz de Lacoue-Labarthe, numa toada divergente daquela de Lyotard, a autora apresenta na nota de rodapé 36 que Kant se mantivera fiel à tradição cujo princípio é creditado a Longino de um "sublime metafísico". Já no tratado do escritor romano é possível encontrar características caras a Kant em sua incursão estética, e que enriquecem ainda mais a forma como encarar o tratado Do sublime. Escreve Figueiredo (2011, p. 47, nota 36): “divergindo da interpretação de Lyotard [...] de um primeiro surgimento do sublime como 'Retórico' e apenas modernamente transformado em 'Filosófico', Lacoue-Labarthe considera que o ‘sublime' dito ‘do pensamento' nascera já com Longino”, demonstrando, também, o quão frágeis são as fronteiras do tempo em filosofia. 
Novamente, é Antonio López Eire quem introduz semelhante interpretação ao encontrar o tratado de Longino. Nele, escreve Eire, pode-se notar uma "teoria da recepção", ou uma “estética da recepção", uma vez que o exercício realizado pelo autor de Do sublime não se volta a inquerir procedimentos psicológicos do autor ao produzir um texto ou de seu leitor ao lê-lo, antes fazendo referência a uma emoção em específico e recusando-se a apontar suas características somente aos procedimentos retórico-discursivos. Do sublime, continua Eire, se refere a um estilo de alta composição capaz de elevar os sentimentos do leitor - esse sentimento elevado não portando outro nome senão sublime (EIRE, 2002, p. 65).

Essas características dificultam a aceitação de retórica para o tratado de Longino. Há um lado em seu texto claramente pertencente a essa corrente da história do pensamento ocidental, mas existem outras características que o levam a fugir de tal categorização. Hypsos não é termo vinculado puramente ao estilo literário e a um punhado de técnicas passíveis de ser destrinchadas e consequentemente reproduzidas e aprendidas. Como já posto anteriormente, Longino deixa muito claro ao princípio do tratado a impossibilidade de se aprender a expressar o sublime; também sendo impossível aprender a experimentar o sublime, dependendo de uma inclinação "de espírito".

Virginia Figueiredo (2011, p. 36) escreve que o belo nasceu grego e, portanto, filosófico, e o sublime nasceu latino e, portanto, retórico; apesar dessa atribuição automática ao universo latino, é importante lembrar que o tratado de Longino foi escrito em grego, como muitos dos escritos retóricos e poéticos do mesmo período. O que faz surgir certo desconforto por parte dos comentadores mais recentes da obra de Longino com a atribuição automática, uma vez que tomando o texto original em mãos descobre-se a vinculação próxima entre Hypsos e Logos algo notado quando Virgínia Figueiredo traz a interpretação de Lacoue-Labarthe a respeito de Longino e sua influência sobre o recebimento moderno (especialmente, em Kant) do sublime: muito dos esforços realizados pelos "estetas" já estava presente no exercício deste "retórico" em particular.

Dada a multiplicidade de traduções e interpretações passíveis de serem feitas do termo grego Logos - e a falta de acesso de muitos intelectuais ao longo dos séculos ao original grego —, é também compreensível a insistência na permanência do tratado de Longino sob uma mesma caracterização de ser um texto técnico sobre como encontrar formas do sublime em literatura. 


\section{IV}

Logos é famosamente um termo de difícil significação e tradução. Seu leque de sentidos abarca termos variados: discurso, linguagem, razão, lógica... Em determinado momento do tratado de Longino, o termo surge em seu plural, logois, sendo traduzido por Marta Isabel de Oliveira Várzeas ora por “discursos”, ora por "textos literários” (LONGINO, 2015, p. 85-86, 33.1). Enquanto isso, na tradução de Filomena Hirata encontramos o termo traduzido de forma mais próxima à aceitação do grande público, "prosa" (LONGINO, 1996, p. 91, XXXIII.1). Ambas as traduções estão adequadas ao conteúdo do parágrafo em questão, designando a distinção entre poesia e prosa, en poiemasi kai logois, se referindo "a todos os gêneros de discurso formalizado e artístico, poético e não poético", escreve Várzeas sobre sua escolha de tradução (LONGINO, 2015, p. 86, nota 161).

Esse é um trecho singular ao longo do tratado de Longino. Nele, é palpável a direção indicada pelo autor ao entendimento do termo como referente a textos escritos dado o seu confronto com o termo poiemasi. Em seu uso geral ao longo do texto, logos pode ser compreendido como o díptico "pensamento e expressão", numa referência ao próprio texto a fornecer o êxtase sublime ao leitor quanto ao próprio sentimento suscitado.

Como Robert Doran captura da interpretação de G. M. A. Grube, o uso de logos por Longino não é uma função unicamente de techné, o que faria referência à arte retórica e à discriminação de variadas técnicas produtoras de sublime que transformariam o tratado num manual de como produzir um texto capaz de levar o leitor/ouvinte ao êxtase sublime. Há a referência à techné, uma vez que Longino busca analisar discursos e demonstrar técnicas utilizadas por seus autores - como já posto anteriormente. Neste caso, logos é função de techné ao mesmo tempo que de noésis (DORAN, 2015, p. 35).

Essa interpretação é evocada ao encontrar o parágrafo 30, iniciado por "dada a íntima ligação entre pensamento e expressão" (LONGINO, 2015, p. 81, 30.1, grifo nosso). Para o mesmo trecho, na tradução de Filomena Hirata encontra-se: "nos discursos, o pensamento e a expressão se desenvolvem..." (LONGINO, 1996, p. 86, XXX, grifo nosso). Enquanto a tradução para o inglês por W. H. Fyfe opta por "since thought and diction [...]" (LONGINO, 1995, p. 263, 30).

As três traduções, com suas variações sutis de uma a outra, demonstram a aproximação de logos (o discurso) tanto de noésis (pensamento, concepção) quanto de phrasis (expressão), esta última uma faceta da techné. As fontes do sublime são um casamento entre estes dois lados, 
a técnica da composição de um discurso e a natural grandiosidade do autor a dominar as técnicas e ser capaz de elevar sua composição (DORAN, 2015, p. 35).

Ou como escreve Marta Isabel de Oliveira Várzeas na introdução à tradução que faz de Longino,

\begin{abstract}
Com a distinção inicial entre o fim para que tende o discurso construído segundo os preceitos da retórica - a persuasão - e o efeito da sublimidade - o êxtase - o autor, de forma que podemos considerar programática, subtrai o sublime ao âmbito da retórica, preparando assim o terreno para poder reclamar para hypsos o estatuto de arte. Na sua perspectiva, a criação de momentos sublimes nos discursos implica necessariamente uma techne que, não sendo totalmente coincidente com a retórica, não a pode dispensar, visto que ela é mesmo o seu necessário ponto de partida. (LONGINO, 2015, p. 17-18).
\end{abstract}

A composição de um texto não vem separada das técnicas para a produção de um discurso, como também não são separadas das capacidades individuais do autor em conceber sua composição. Há uma dialética em jogo entre os meios e as formas para compor um texto, em que a importância da compreensão dos efeitos no leitor não pode ser ignorada. No sublime de Longino, o autor se vale de técnicas, mas as técnicas puras não levam ao sublime, é necessária sua disposição intelectiva para a composição de momentos de êxtase sublime. Mas esses momentos não podem ser alcançados por qualquer leitor/ouvinte ao se deparar com uma obra grandiosa, é necessário disposição também por parte de quem ler/escutar uma composição. Também não se pode chamar de sublime o trecho puro da obra analisada: Longino faz muitas referências a momentos sublimes em composições de grandes autores do passado, mas essa sublimação não pertence unicamente ao texto, o leitor/ouvinte disposto à elevação é quem será capaz de diferenciar a singularidades desses momentos.

\title{
V
}

Uma das características recorrentes do sublime em seus muitos autores ao longo dos séculos é sua ligação com a ética. Longe de ser uma noção pertencente exclusivamente à poética e à estética, como seria de imediata concepção, o sublime guarda mais esta surpresa aos estudiosos. Essa dimensão ética pode ser encontrada nos autores modernos, mas já mostrava suas caras em Longino.

Escrevendo sobre a natureza humana com o auxílio do termo logos, evocando a grandeza interior para conceber o sublime — tanto de autores quanto de receptores da obra - 
fica patente a presença de uma dimensão ética no tratado Do sublime (SHAW, 2006, p. 18). Como escreve Eire, numa nota de rodapé discriminada na introdução de Marta Várzeas à sua tradução do tratado de Longino, o sublime não é uma qualidade estética tornada ética, antes sendo uma qualidade ética tornada estética (LONGINO, 2015, p. 16).

Marta Várzeas, ainda em sua introdução, aponta para um dos trechos mais notáveis do tratado para indicar a presença da "ética feita estética", seguindo os termos de Eire. Nele, Longino escreve sobre o silêncio de Ájax no canto 11 da Odisseia. Ao encontrar Ulisses no Hades e dar-lhe as costas, Ájax demonstra a grandeza interior (assim Marta Várzeas traduz megalophrosyne) ao partir sem pronunciar palavra (LONGINO, 2015, p. 48, 9.2). É tamanho o conflito criado pela ausência de palavras entre as duas personagens que, mais tarde, este mesmo encontro renderia uma tragédia pelas mãos de Sófocles - Ájax.

No mesmo parágrafo 9, mas em sequência ao trecho do silêncio de Ájax, Longino escreve: "é absolutamente necessário começar pela questão fundamental de saber donde vem o Sublime” (LONGINO, 2015, p. 48, 9.3). Não é a técnica do discurso e de sua apresentação que está na mente do autor, antes a inclinação racional de quem seria capaz de criar um momento sublime. Continua Longino (2015, p. 48, 9.3): "Não é possível que quem passa toda a sua vida entregue a pensamentos mesquinhos e a ocupações servis produza algo espantoso e digno de fama para sempre." Um dos pressupostos do verdadeiro sublime é a sua persistência ao teste do tempo; portanto, alcançar o sublime seria próprio de quem pensa para além de suas próprias ocupações, mais preocupado com algo de mais grandioso, como o eterno.

Apontando para o fato de o tratado ter sido escrito no cenário da democracia romana, Philip Shaw mostra que certos detalhes dessa dimensão ética do sublime de Longino parecem distanciá-lo das prerrogativas democráticas. Dois pontos em particular podem ser apontados para essa interpretação: primeiro, a impossibilidade de ensinar o sublime a qualquer pessoa e a impossibilidade de qualquer pessoa ser capaz de alguma vez experimentar o sublime; segundo, no mesmo trecho citado acima a passagem "ocupações servis". Ambos os pontos parecem apontar para um Longino abraçando a nobreza não somente das ideias, como também a nobreza social.

Robert Doran defende que, apesar de utilizar exemplos de nobres como Alexandre Magno para indicar aqueles indivíduos dotados de grandeza interior, o tratado de Longino não dá preferência àqueles socialmente nobres. Como demonstração de seu ponto, Doran mostra 
que os mais constantemente selecionados por Longino a elencar o "heroísmo" da grandeza interior são personagens vindos de castas mais baixas da sociedade - em comparação com nobres como Alexandre Magno - que são os poetas, os filósofos, os historiadores e oradores. Defende Doran:

[...] não há uma hierarquia baseada em classe implícita na concepção de Longino de hypsos; há uma hierarquia de mentalidades, que pode ou não corresponder a um determinado estrato social. [...] A separação efetiva realizada por Longino entre o sublime e seus determinantes sociais em sua noção do escritor-herói terá repercussões importantes. Prefigura a exaltação do gênio no Romantismo, e, mais genericamente, a ideia de nobreza de espírito como qualidade mental intrínseca anunciando o ideal de uma sociedade meritocrática — uma aristocracia do talento (DORAN, 2015, p. 63, tradução nossa).

Apesar de sua defesa para uma cegueira de classes por parte de Longino, a parte final deste parágrafo — a citação acima — aponta para a manutenção da interpretação de Philip Shaw a respeito do favorecimento de classes mais altas pelo que Longino compreenderia por quem seriam aqueles capazes de alcançar o sublime. $O$ gênio precisaria ser nutrido para alcançar o sublime, o que não aconteceria caso este mesmo gênio fosse entregue a "ocupações servis".

É ao final do tratado, quando relata a Terenciano uma conversa tida com outro filósofo, que Longino apontará algo próximo do que tenta defender Doran: a nobreza para alcançar o sublime não tem relação com seu status social, mas, antes, com sua grandeza interior. Escreve Longino a esse respeito:

[...] não é a paz do mundo que destrói os grandes talentos, mas muito mais essa guerra sem fim que toma conta dos nossos desejos e ainda, por Zeus, aquelas paixões que dominam a vida moderna e a conduzem e arrebatam completamente. É o amor insaciável da riqueza, do qual todos padecemos, e o amor dos prazeres que nos escravizam e, mais ainda, afundam a vida com os homens lá dentro. (LONGINO, 2015, p. 101, 44.6).

Ainda sobre esse trecho, Philip Shaw (2006, p. 18) escreve que o sublime eleva as pessoas acima de suas preocupações com riquezas ou status. Contudo, continua Shaw, essa relação entre a noção de sublime e a riqueza permanece sendo meramente formal, enquanto Longino continua o mesmo parágrafo de encerramento de seu tratado. A riqueza seria mais perigosa quando seu poder não pudesse ser medido. A grandeza das riquezas financeiras não é

\footnotetext{
${ }^{1}$ Termo de Doran.
} 
suficiente para "elevar a alma", nas palavras de Shaw, pelo contrário, levando à ruína. Shaw conclui: "o verdadeiro sublime está do lado da moralidade".

\section{VI}

São três termos distintos frequentemente trabalhados e traduzidos em uma mesma noção. O grego hypsos, o alemão das Erhabene, o latino sublimis, também presente na língua inglesa. Apesar de traduzidos por um mesmo termo, sublime, cada um desses idiomas insere conotações próprias ao entendimento da noção. Longino trabalhava com hypsos, Kant com Erhabene, e a tradição francesa, inglesa e estadunidense com sublime (a exemplo do britânico Edmund Burke, do francês Jean-François Lyotard, e do italiano Mario Costa).

O termo de origem latina sublime abarca todas as demais noções por nascer da leitura do hypsos de Longino e buscar abarcar novos sentidos. O termo alemão, das Erhabene é o que mais se aproxima da noção grega, favorecendo a interpretação de alguns comentadores a respeito da proximidade entre o sublime kantiano e o sublime longiniano (como visto ser o caso da interpretação de Laoue-Labarthe). Isso porque o termo utilizado por Kant na Crítica da faculdade do juízo, a terceira crítica, é o que pode ser entendido como sendo "elevação", assim como acontece com o termo hypsos (DORAN, 2015, p. 23, nota de rodapé 76).

Tanto no termo alemão quanto no termo grego, há uma semelhança na busca pela elevação (o exercício interno), assim como pelo levante (exercício externo), o que poderia ser compreendido tanto pelo exercício da razão em buscar a grandeza, quanto receber um estímulo externo e ser levado à grandeza. O lado da tentativa externa é identificado em Longino por meio de suas análises do sublime em literatura, enquanto em Kant poder-se-ia enxergar um esforço de se aproximar da elevação interna ${ }^{2}$. Não estranha, portanto, que estes sejam os dois autores que mais deem atenção ao lado ético do sublime, apesar de Longino apontar sua origem natural, dispensada por Kant.

O termo latino sublimis, utilizado nas traduções latinas do texto de Longino e adotado por Nicolas Boileau em sua tradução para o francês que deu notoriedade ao tratado em questão, era frequentemente utilizado para se referir a estilo ao invés de possuir uma atribuição estética — tal como esse termo veio a ser compreendido a partir do século XVIII. O estilo elevado era chamado de sermo gravis ou sublimis (AUERBACH, 2017 p. 132). Foi Boileau, em sua

\footnotetext{
2 "Do belo da natureza temos que procurar um fundamento fora de nós; do sublime, porém, simplesmente em nós e na maneira de pensar que introduz à representação da primeira sublimidade.” (KANT, 2012, p. 91, 78).
} 
introdução à tradução do tratado de Longino, um dos responsáveis por adicionar à noção de sublime características éticas e estéticas.

Enquanto isso, o hypsos de Longino e a das Erhabene de Kant aproximam-se de suas noções de ética e moralidade por meio de um alcance em similar: a liberdade. A elevação dirige a uma autossuficiência; como visto, Longino aponta para uma libertação da mesquinharia e dos desejos de lucro, em suma evocando a liberdade do que seria apontado por ele como coisas pequenas impedindo o caminho à elevação. Kant (2012, p. 127, 126) escreve a esse respeito: "Ser autossuficiente, por conseguinte não precisar de sociedade, sem ser com isso insociável, isto é fugir dela, é algo que se aproxima do sublime, assim como toda liberação de necessidades."

É viver em sociedade sem ser preso aos seus ditames, dispondo de perfeita emancipação intelectual, sem adicionar a essa emancipação causas sensíveis; essa ideia pode ser iluminada pela sublimidade da desolação: "a desolação [...] pode ser contada entre os afetos vigorosos se ela tem seu fundamento em ideias morais" (KANT, 2012, p. 128, 128). As ideias morais estariam para além da sensibilidade e de suas necessidades: “a lei moral, porém, é, em si mesma, suficiente e originalmente determinante em nós" — enquanto que "[...] o sublime não deve ser procurado nas coisas da natureza ${ }^{3}$, mas unicamente em nossas ideias" (KANT, 2012, p. 95, 84). Em suma, a libertação da mesquinharia em caminho à elevação.

Em última conta, o sublime tratado por Longino e por Kant possuem semelhantes inclinações à elevação não somente em seu aspecto estético, como também em seu aspecto ético-moral.

\section{VII}

A tradição latina interpretava sublimis como um alto estilo de composição, contra o qual era possível opor humilis, o estilo baixo de linguagem. A tradução do hypsos de Longino por sublimis, a um primeiro momento levou a concepção longiniana a perder muito de sua originalidade, num segundo momento auxiliou a incrementar o termo latino. Isso veio com um custo para o tratado Do sublime: caracterizado como pertencente à tradição retórica, sua noção de sublime foi apontada como sendo recurso de uma poética analisando um punhado de obras

\footnotetext{
${ }^{3}$ Este é o principal rompimento entre Kant e Longino, uma vez que hypsos tem origem natural.
} 
clássicas da literatura grega. Do sublime é um tratado pertencente à tradição retórica, mas deve ser guardado numa prateleira separada das demais poéticas escritas no período.

A originalidade do texto é também seu ponto de dificuldade: a relação entre logos e hypsos. O termo logos pode ser traduzido por discurso e razão, aponta para uma tendência a interpretar o tratado de Longino como um esforço de destrinchar uma técnica discursiva. A sutileza reside em enxergar que o logos ali utilizado faz menção a um sublime extratextual, a uma emoção que pode ser suscitada por uma obra literária, mas que floresce numa grandeza interior.

A utilização de logos por Longino indica o sublime das grandes ideias — novamente ganhando eco na história da filosofia com o sublime kantiano. Este é um dos pontos que vale a pena ressaltar no tratado: as obras analisadas por Longino não possuem uma unidade de gênero, são textos em verso e prosa, discursos e tragédias, até os diálogos platônicos e o velho testamento da bíblia judaica. O sublime está onde as grandes ideias surgem.

Do sublime oferece uma contribuição estética para a compreensão da emoção do sublime. Sua visão a respeito dessa emoção não deixa o sublime refém de uma relação de causa e efeito com uma obra literária. Pelo contrário, não é possível ensinar o sublime, apenas quem é disposto a ser elevado por grandes ideias será capaz de se comover com uma passagem como esta.

Compreensão estética do sublime no sentido de poder acompanhar o desenrolar desta noção para além das técnicas de composição discursiva. Notar o aparecimento do sublime mesmo fora do contexto de criação de uma obra literária, ou a reverberação do sublime numa moral. Longino pode ter seu sublime investigado para além de seus atributos retóricos do "bom escrever”, inserindo-o numa realidade filosófica de inquérito da própria razão.

\section{REFERÊNCIAS}

AUERBACH, Erich. Mimesis. Tradução: Vários tradutores. São Paulo (Brasil): Editora Perspectiva, 2017.

DORAN, Robert. The theory of the sublime, from Longinus to Kant. Cambridge (Reino Unido): Cambridge University Press, 2015.

EIRE, Antonio López. Retórica clássica y teoría literaria moderna. Madrid (Espanha): Arco Libros, 2002.

FIGUEIREDO, Virgínia. O sublime explicado às crianças. Trans/Form/Ação, Marília, v. 34, p. 35-56, 2011. 
KANT, Immanuel. Crítica da faculdade do juízo. Tradução de Valério Rohden, António Marques. Rio de Janeiro (Brasil): Forense Universitária, 2012.

LONGINO. Do sublime. Tradução de Filomena Hirata. São Paulo (Brasil): Martins Fontes, 1996.

LONGINO. Do sublime. Tradução, introdução e comentário de Marta Isabel de Oliveira Várzeas. Coimbra (Portugal), São Paulo (Brasil): Imprensa da Universidade de Coimbra, Annablume Editora, 2015.

LONGINO. On the sublime. Tradução de W. H. Fyfe. Cambridge (EUA): Harvard University Press, 1995.

SHAW, Philip. The sublime. Nova York (EUA): Routledge, 2006.

VÁRZEAS, Marta Isabel de Oliveira. Introdução. In: LONGINO. Do sublime. Tradução, introdução e comentário de Marta Isabel de Oliveira Várzeas. Coimbra (Portugal), São Paulo (Brasil): Imprensa da Universidade de Coimbra, Annablume Editora, 2015. 